\title{
Invited Commentary Special Section: The Role of Official Statistics in Statistical Capacity Building
}

\author{
John Pullinger ${ }^{1}$
}

\section{Introduction and Outline}

The United Nations Fundamental Principles of Official Statistics place official statistics as an indispensable element in the information system of a democratic society (United Nations Economic and Social Council 2013). In that light, official statistics are themselves a critical element of national capability, providing a trustworthy foundation for decision makers and an essential tool for citizens to make good choices in their own lives. Official statistics also hold decision makers, in the public and private sectors, to account.

The capacity built within systems of official statistics is also part of wider civil society. This capacity supports a wider infrastructure within nations, regions, and globally, incorporating academia, business, and civil society, including national statistical societies and the International Statistical Institute.

Equally, statistical capacity developed through the education system in schools and universities and through continuous professional development in businesses, provides a statistical ecosystem that is mutually reinforcing, fostering a resource that can benefit official statistics as well as other fields of endeavour.

Especially salient is statistical literacy, which needs to be nurtured within all parts of society including amongst politicians, officials, and the media as well as in the worlds of finance, commerce, and academia. High levels of statistical literacy in society create a virtuous circle - the greater the statistical expertise of the using community the greater the demand for high quality data.

The current imperative to build statistical capacity of official statisticians as discussed by Deutsch, as well as Forbes and Keegan in the special section of this issue, is strong as data becomes the defining resource of our age. The ability to mobilise the power of data to help individuals, organisations, and states make better decisions is becoming the differentiator between those who thrive and those who fail to do so.

\section{Context - History and Current}

The root of the word statistics hints at the fundamental value it has in the effective functioning of a state. Notions from the 18th century that the purpose of statistics is to improve the quantum of happiness of the people reference its potential to empower citizens and transform lives (Pullinger 2013). However, information is always associated with power, and that power can be used benevolently or malevolently. A vital aspect of the

\footnotetext{
${ }^{1}$ National Statistician, UK Statistics Authority, 1 Drummond Gate, London SW1V 2QQ, UK. Email: national.statistician@statistics.gov.uk
} 
public value of statistics is openness - helping to challenge decisions as well as to make them.

The history of official statistics in many nations links to the ups and downs of the countries themselves. In several instances (positive and negative) critical moments in official statistics parallel critical moments for the nation (Seltzer 1994).

This is also so at the international level. The role of the Conference of European Statisticians during the period before 1989 enabled it to be ready in the years afterwards to play a pivotal role in supporting the new democracies of Central and Eastern Europe. These nations needed to develop statistical capability, by, among other things, the adoption of fundamental principles of official statistics. These principles were taken up by other regions and finally adopted by the United Nations General Assembly in 2014, the same year as the UN Secretary General published his report on the impact of the data revolution on global development (United Nations 2014b), emphasising the need for continuous evolution of official statistics, which MacFeely discusses in the special section of this issue.

\section{Official Statistics as a Part of National and Global Capacity}

Over the last two years the role of official statistics as part of national and global capacity has been given sharpened focus by the adoption by the UN General Assembly of Sustainable Development Goals for the period 2015-2030 (United Nations Department of Economic and Social Affairs 2014). The goals include specific proposals to provide the means of implementation for the ambitions set out. These include enhanced capacity-building support to developing countries to increase significantly increase the availability of high-quality, timely, and reliable data disaggregated by income, gender, age, race, ethnicity, migratory status, disability, geographic location, and other characteristics relevant in national contexts (United Nations 2014a). The agreement reached in Addis Ababa on financing for development provides a strong underpinning for this in the call for international support and partnerships for implementing effective and targeted capacity-building in developing countries (United Nations Department of Economic and Social Affairs 2015).

The United Nations Statistical Commission has now agreed on a package of indicators to provide a practical starting point for measuring progress on sustainable development in the years ahead. There is work to be done in all countries but especially in Africa, the least developed countries, landlocked developing countries, and small island developing states. The world data forum that takes place in South Africa in 2017 will provide an opportunity for partners from all sectors to meet and consider how best to work together to build the capability required (United Nations Statistical Commission 2016).

The history of statistical capacity building merits detailed reflection. Despite the valiant work of PARIS21 (Soremho-Ramos 2015) and others arising from the follow up to the Millennium Development Goals, sustained and successful capacity development remain elusive. We must learn from this experience to be more successful in the years ahead.

\section{Official Statistics Supporting National Statistical Capability}

Of course, official statistics themselves already provide a resource that can help grow wider capability. As an employer, National Statistical Institutes can draw on academic 
training and there are many examples of positive symbiosis. The European Union Masters in Official Statistics programme is an example (Eurostat (n.d.)). The plan in the UK to develop an Economic Statistics Centre of Excellence is another highlighting an increasing trend towards using partnership approaches to develop capacity in the medium term (Office for National Statistics 2016).

At another level, the services provided by statisticians can help generate innovation and entrepreneurship in other sectors. The UK has been in vanguard of supporting Open Data with many positive outcomes across the economy (Open Government Partnership (n.d.)), also highlighting benefits for small and medium-sized enterprises, which Coleman details in the special section of this issue. Other UK initiatives, such as the Justice Data Lab, that enables third sector organisations to benefit from statistical analysis of sensitive data without compromising confidentiality, can provide a boost to the contribution statistics makes to wider society (Ministry of Justice 2014). Another example is the Integrated Data Infrastructure in New Zealand, which has helped solve complex issues such as on crime and vulnerable children to improve outcomes for citizens (Statistics New Zealand 2016).

\section{National Statistical Capability Supporting Official Statistics}

Mutual dependence goes further. Official statistics in a country benefits enormously from a vibrant national statistical capability in the wider community. Of particular importance is the role of national statistical societies (and at the global level of the International Statistical Institute). The Royal Statistical Society (RSS) for example has instituted a strategy designed to play a pivotal role in supporting statistical systems. The strategy is focused on four core themes: the discipline of statistics; the statistical profession; statistics in public policy; and statistical literacy (Royal Statistical Society 2013). All of these areas benefit and add capability to official statistics and reflect the public value offered by strong statistical communities in universities, in workplaces (especially those that recognise the contribution made by chartered statisticians), and in the public realm.

The nurturing of statistical literacy has a special place. Indeed, the adoption of the Royal Statistical Society strategy was accompanied with the launch of the Getstats campaign for statistical literacy (Royal Statistical Society (n.d.)). The campaign was designed to raise levels of statistical understanding across society and thereby raise national statistical capability. The campaign focused initially on two critical groups - politicians and the media. Seminars and skills training opportunities for Members of Parliament and their staff were well received. Journalists had already had strong engagement with the RSS awards for statistical excellence and were ready to take up further opportunities (Royal Statistical Society 2016). These examples show that when statistics presents itself as something that can help people do their own jobs better, they will want to get involved. Statistics also complement wider developments such as the review of the way the BBC used statistics in the most recent UK general election (BBC Trust 2016).

Within schools, initiatives such as CensusAtSchool has demonstrated the value of good curriculum based materials in the classroom (CensusAtSchool UK (n.d.)). This and other initiatives paved the way to make the case for better statistical and data curriculum content across the age and subject range, especially in the 16-18 age group. Also at university level, the Q-Step programme developed by the Economic and Social Research 
Council and the Nuffield Foundation has provided quantitative training for university students of a wide variety of social science disciplines from politics to sociology (Nuffield Foundation. (n.d.)).

Another valuable initiative has been that taken by the policy profession in the UK civil service to incorporate statistical training in the core curriculum for their professional development. What links all these initiatives is the fact that if the consumers of official statistics are more statistically literate they will be better able to get value from them. They will also be likely to be more critical of what they get, thereby helping to drive up quality in a virtuous circle.

The role of official statistics in statistical capacity building can thus be characterised as the combination of developing both the supply side and the demand side of the equation.

\section{The Opportunity of the Data Revolution}

The data revolution presents an opportunity to turn this analysis into action in a profound way. As data becomes the defining resource of our age, those who can add value to that resource and create meaning and insight from it will have a special contribution to make to our economies and societies. The thinking required is illustrated by the idea of moving from quality to information quality, see Kenett and Shmueli in the special section of this issue. Building the data capability of statistical organisations is thus a pressing imperative. At the global level there is the potential for a grand partnership between governments, businesses, and civil society. There is an opportunity for those with a special position linking these communities to step up. The International Statistical Institute, International Association of Official Statisticians, International Association of Statistical Education and many others have much to contribute. Similarly within the regions and nations there are partnerships to be encouraged.

In the UK, the mutual benefits accruing to UK official statistics and the Royal Statistical Society from a vibrant relationship could inspire others.

The launch of a Data Science Campus at the ONS headquarters in Newport is a symbol to the organisation and to the nation that we are taking that opportunity (Office for National Statistics (n.d.)). At the heart of our strategy is the enhancement of technological and human capability with major investments in a learning academy for our staff and apprenticeships to train the next generation of colleagues (Office for National Statistics 2014). We are also ready reach out and make common cause with those interested in the development of official statistics that serve the public good. Central to this is the desire to work with colleagues in other countries, especially those who struggle to access the necessary resources internally. Here we can work with UN and other agencies to form new kinds of partnerships and together mobilise the power of data to help the world make better decisions.

\section{References}

BBC Trust. 2016. "BBC Trust Impartiality Review: Making Sense of Statistics." Available at: http://downloads.bbc.co.uk/bbctrust/assets/files/pdf/our_work/stats_ impartiality/report.pdf (accessed September 2016). 
CensusAtSchool UK. (n.d.). Welcome to CensusAtSchool UK. Available at: http://www. censusatschool.com/ (accessed September 2016).

Eurostat. (n.d.). European Master in Official Statistics. Available at: http://ec.europa.eu/ eurostat/web/european-statistical-system/emos (accessed September 2016).

Ministry of Justice. 2014. Accessing the Justice Data Lab service. Available at: https://www.gov.uk/government/publications/justice-data-lab (accessed September 2016).

Nuffield Foundation. (n.d.). Q-Step. Available at: http://www.nuffieldfoundation.org/ q-step (accessed September 2016).

Office for National Statistics. 2014. "Better Statistics, Better Decisions: Strategy for UK statistics, 2015 to 2020." Strategy launched on 1 November 2014. Available at: https://www.statisticsauthority.gov.uk/archive/news/uk-statistics-authority-statementof-strategy-2015-2020-better-statistics-better-decisions.pdf (accessed September 2016).

Office for National Statistics. 2016. Economic Statistics Centre of Excellence. Available at: https://www.ons.gov.uk/news/statementsandletters/economicstatisticscentreofexcellenceescoe (accessed September 2016).

Office for National Statistics. (n.d.). Data Science Campus. Available at: https://www.ons. gov.uk/aboutus/whatwedo/datasciencecampus (accessed September 2016).

Open Government Partnership. (n.d.). United Kingdom. Available at: http://www. opengovpartnership.org/country/united-kingdom (accessed September 2016).

Pullinger, J. 2013. "Statistics Making an Impact." Journal of the Royal Statistical Society, Series A (Statistics in Society) 176: 819-839. Doi: http://dx.doi.org/10.1111/rssa. 12023.

Royal Statistical Society. 2013. Strategic Plan 2014-18: A World with Data at the Heart of Understanding and Decision Making. Available at: https://www.rss.org.uk/Images/ PDF/about/strategy-summary_flr.pdf (accessed September 2016).

Royal Statistical Society. 2016. Statistical Excellence in Journalism. Available at: http:// www.rss.org.uk/RSS/About/Recognising_Statistical_Excellence/Journalism_awards/ RSS/About_the_RSS/Recognising_statistical_excellence_sub/Statistical_Excellence_ in_Journalism_Awards.aspx?hkey=f10b8e1e-466a-4ef1-af2a-f8f53e04f338 (accessed September 2016).

Royal Statistical Society. (n.d.). Statistical Literacy. Available at: http://www.rss.org.uk/ RSS/Influencing_Change/Statistical_literacy/RSS/Influencing_Change/Statistical_literacy. aspx?hkey=821bf2f4-8a09-413c-8d22-290e2209a92a (accessed September 2016).

Seltzer, B. 1994. "Politics and Statistics: Independence, Dependence or Interaction?". Department for Economic and Social Interaction and Policy Analysis Working Paper Series No. 6. Available at: http://unstats.un.org/unsd/statcom/FP-Seltzer.pdf (accessed September 2016).

Soremho-Ramos, S. 2015. "Paris21: Light Evaluation of Paris21, Final Report." Report published February 2015 commissioned at the Paris21 Board Meeting in 2014. Available at: http://www.paris21.org/sites/default/files/PARIS212015-Evaluation_0. pdf (accessed September 2016). 
Statistics New Zealand. 2016. The Integrated Data Infrastructure. Available at: http:// www.stats.govt.nz/browse_for_stats/snapshots-of-nz/integrated-data-infrastructure. aspx (accessed September 2016).

United Nations. 2014a. Sustainable Development Goal 17: Strengthen the Means of Implementation and Revitalize the Global Partnership for Sustainable Development. Available at: https://sustainabledevelopment.un.org/sdg17 (accessed September 2016).

United Nations. 2014b. "A World That Counts: Mobilising the Data Revolution for Sustainable Development." Report prepared at the request of the United Nations Secretary-General, by the Independent Expert Advisory Group on a Data Revolution for Sustainable Development. Available at: http://www.undatarevolution.org/wp-content/ uploads/2014/11/A-World-That-Counts.pdf (accessed September 2016).

United Nations Department of Economic and Social Affairs. 2014. Sustainable Development Goal indicators. Available at: http://unstats.un.org/sdgs/ (accessed September 2016).

United Nations Department of Economic and Social Affairs. 2015. Addis Ababa Action Agenda: of the Third International Conference on Financing for Development. Available at: http://www.un.org/esa/ffd/wp-content/uploads/2015/08/AAAA_ Outcome.pdf (accessed September 2016).

United Nations Economic and Social Council. 2013. "Fundamental Principles of Official Statistics." Resolution adopted by the Economic and Social Council on 24 July 2013. Available at: http://unstats.un.org/unsd/dnss/gp/FP-Rev2013-E.pdf (accessed September 2016).

United Nations Statistical Commission. 2016. High Level Forum of Official Statistics: Dialogue Towards the UN World Data Forum. Meeting 7 March 2016 organised by the United Nations Statistics Division. Available at: http://unstats.un.org/unsd/statcom/ 47th-session/side-events/20160307-3A-towards-un-world-data-forum/ (accessed September 2016). 